\title{
Growth and characterization of epitaxial ultra-thin NbN films on 3C-SiC/Si substrate for terahertz applications
}

\author{
D Dochev ${ }^{1}$, V Desmaris ${ }^{1}$, A Pavolotsky ${ }^{1}$, Meledin ${ }^{1}$, Z Lai $^{2}$, A Henry ${ }^{3}$, E Janzén ${ }^{3}$, \\ E Pippel $^{4}$, J Woltersdorf ${ }^{4}$ and V Belitsky ${ }^{1}$ \\ ${ }^{1}$ Group for Advanced Receiver Development, Department of Radio and Space \\ Science, Chalmers University of Technology, SE-412 96 Gothenburg, Sweden \\ ${ }^{2}$ Nanofabrication Laboratory, Department of Microtechnology and Nanoscience, \\ Chalmers University of Technology, SE-412 96 Gothenburg, Sweden \\ ${ }^{3}$ Department of Physics, Chemistry and Biology, Linköping University, SE-581 83 \\ Linköping, Sweden \\ ${ }^{4}$ Max-Planck-Institute of Microstructure Physics, Weinberg 2, D-06120 Halle, \\ Germany \\ E-mail: dimitar.dochev@chalmers.se
}

\begin{abstract}
We report on electrical properties and microstructure of epitaxial thin $\mathrm{NbN}$ films grown on $3 \mathrm{C}-\mathrm{SiC} / \mathrm{Si}$ substrates by means of reactive magnetron sputtering. A complete epitaxial growth at the $\mathrm{NbN} / 3 \mathrm{C}-\mathrm{SiC}$ interface has been confirmed by means of high-resolution transmission electron microscopy (HRTEM) along with $\mathrm{x}$-ray diffractometry (XRD). Resistivity measurements of the films have shown that the superconducting transition onset temperature $\left(T_{\mathrm{C}}\right)$ for the best specimen is $11.8 \mathrm{~K}$. Using these epitaxial $\mathrm{NbN}$ films, we have fabricated submicron-size hot-electron bolometer (HEB) devices on $3 \mathrm{C}-\mathrm{SiC} / \mathrm{Si}$ substrate and performed their complete DC characterization. The observed critical temperature $T_{\mathrm{C}}=11.3 \mathrm{~K}$ and critical current density of about $2.5 \mathrm{MA} / \mathrm{cm}^{2}$ at $4.2 \mathrm{~K}$ of the submicron-size bridges were uniform across the sample. This suggests that the deposited $\mathrm{NbN}$ films possess the necessary homogeneity to sustain reliable hot electron bolometer device fabrication for $\mathrm{THz}$ mixer applications.
\end{abstract}

\section{Introduction}

Hot-electron bolometers (HEB) mixers based on superconducting ultrathin $\mathrm{NbN}$ films are largely used for $\mathrm{THz}$ spectroscopy for space [1] and ground-based [2-4] observations. To date, the state-of-the-art HEB mixers are used for frequency range of $1.2-5.2 \mathrm{THz}[1,5-7]$ with the noise performance ranging 10 to 15 times of the quantum noise on respective frequency.

The intermediate frequency (IF) gain bandwidth for HEB mixers is determined by their ability to cool down quickly. The currently used phonon-cooled HEB mixers are vastly dependent on the heat transfer rate between the superconducting film and the substrate. The material parameters such as the thickness $(d)$ of the superconducting film, and its acoustic match $(\alpha)$ with the substrate largely define this process [8]. The critical temperature $\left(T_{\mathrm{C}}\right)$ is important to ensure fast cooling of hot electrons trough interactions with phonons. A variety of available single crystal substrates such as quartz, silicon, sapphire and $\mathrm{MgO}$ are employed with the $\mathrm{NbN}$ films when it comes to HEB mixers. 
Crystal quartz is usually the preferred choice when it comes to waveguide $\mathrm{THz}$ mixers because of its low dielectric permittivity and RF loss. However, HEBs on quartz substrates suffer from relatively narrow IF gain bandwidth of about $2 \mathrm{GHz}$ [9], which could be insufficient for, e.g., radio astronomy applications. Silicon material is also an attractive substrate candidate due to its low loss at $\mathrm{THz}$ frequencies and maturity of the processing technology. Nevertheless, the IF bandwidth is typically measured to be 3-4 GHz [10]. Cubic $\mathrm{MgO}$ substrate demonstrates a good lattice match with the B1$\mathrm{NbN}$, which results in IF bandwidth of $5.2 \mathrm{GHz}$ with an $\mathrm{MgO}$ buffer layer on $\mathrm{Si}$ [11] and $3.7 \mathrm{GHz}$ with a $\mathrm{MgO}$ buffer layer on crystal quartz [12], respectively. Still, the relatively large dielectric constant $\left(\varepsilon_{\mathrm{r}}=9.6\right)$, hygroscopic properties [13] and sensitivity to acids and alkaline solutions surface [14] hinder the usage of $\mathrm{MgO}$ as an ultimate substrate material for $\mathrm{THz}$ waveguide mixer applications. Sapphire is also known to be a good substrate material for epitaxial growth of $\mathrm{NbN}$ [15]. However, its relatively high dielectric constant $\left(\varepsilon_{\mathrm{r}}=9.3-11.5\right)$ and processing challenges compared to that of quartz are of major concern for waveguide HEB mixers.

Another possible solution to further increase the IF bandwidth and overcome the existing problems is to use a monocrystalline $3 \mathrm{C}$ - $\mathrm{SiC}$ substrate [16], thus providing a necessary lattice match $(\sim 1 \%)$ and, hence, proper conditions for epitaxial growth of $\mathrm{NbN}$ thin films. Earlier, $\mathrm{NbN}$ deposition over $3 \mathrm{C}-\mathrm{SiC}$ has been reported $[14,17]$. However, no attempts has been made neither to fabricate practical HEB devices out of the NbN ultra-thin films prepared over 3C-SiC substrate, nor systematically study of the device electrical properties.

In this paper, we present the results of material characterization of epitaxially grown ultra-thin $\mathrm{NbN}$ films on 3C-SiC/Si substrates, deposited by means of DC magnetron reactive sputtering. Results of complete DC characterization of fabricated $\mathrm{NbN}$ HEB devices with various bridge sizes on $3 \mathrm{C}-\mathrm{SiC} / \mathrm{Si}$ substrate are reported. These results provide an evidence of the deposited $\mathrm{NbN}$ film uniformity, which makes it useful for fabricating of practical devices for THz electronics, e.g., hot-electron bolometers.

\section{Experiment}

\subsection{Fabrication}

Single crystal 3C-SiC films were grown in a hot-wall chemical vapor deposition reactor (CVD) [18] on $100 \mathrm{~mm}$ diameter p-type boron-doped (100) Si wafers. Compared to cold-wall reactor employed in [17], the concept of hot-wall reactor provides a higher heating- and cracking-efficiency of the hydrocarbons [19]. The carrier gas was hydrogen purified through heated palladium cells mixed with $2 \%$ of Ar. Silane $\left(\mathrm{SiH}_{4}\right)$ and propane $\left(\mathrm{C}_{3} \mathrm{H}_{8}\right)$ were used as precursors. The $\mathrm{Si} / \mathrm{H}_{2}$ ratio was typically $0.024 \%$ and the $\mathrm{C} / \mathrm{Si}$ ratio 1 . The growth temperature was always $1350^{\circ} \mathrm{C}$ and the pressure $300 \mathrm{mbar}$. The low pressure allows achieving high quality epilayer with low background level of impurities and excellent uniformity compared to atmospheric pressure growth, as in [17], since higher flow velocity is obtained. In addition, a carbonization layer prior the $3 \mathrm{C}$ growth was made using maximum propane flow, allowed by the system through the susceptor, before and during the temperature ramp up. The $3 \mathrm{C}-\mathrm{SiC}$ films were undoped and had a thickness of about $2 \mu \mathrm{m}$.

The $\mathrm{NbN}$ films were grown on preheated $\left(\sim 800^{\circ} \mathrm{C}\right) 3 \mathrm{C}-\mathrm{SiC} / \mathrm{Si}$ substrates by means of reactive DC magnetron sputtering in a $\mathrm{Ar} / \mathrm{N}_{2}$ gas mixture using a $\mathrm{Nb}$ target with a diameter of 2-inch. Prior to loading in the sputtering system, the substrates have been chemically cleaned from organic contaminants in a 5:1:1 mixture of deionized water, $\mathrm{NH}_{4} \mathrm{OH}$ and $\mathrm{H}_{2} \mathrm{O}_{2}$. Native oxides have been treated by means of buffered oxide etch (BOE) solution. The background pressure prior deposition was $2.7 \times 10^{-6} \mathrm{~Pa}$. During the reactive sputtering the $\mathrm{Ar} / \mathrm{N}_{2}$ gas mixture with $10: 1 \mathrm{flow}$ ratio was used at a total pressure of $0.68 \mathrm{~Pa}$. The DC magnetron current to the target was set to $0.5 \mathrm{~A}$ and the resulting deposition rate for the $\mathrm{NbN}$ film was $75 \AA / \mathrm{min}$. The deposition rate was verified by the film thickness measurement via the transmission electron microscopy (TEM) and X-ray diffractometry on satellite $\mathrm{NbN} / \mathrm{Si}$ specimens.

The HEB devices were fabricated using a $12 \times 6 \mathrm{~mm}^{2} 3 \mathrm{C}-\mathrm{SiC} / \mathrm{Si}$ substrate, on which $\mathrm{NbN}$ film was deposited. The bolometer length was defined by the separation between its contact pads, in our case 
ranging from $100 \mathrm{~nm}$ to $400 \mathrm{~nm}$; the pads were defined by electron-beam lithography (EBL) using a bilayer PMMA/Copolymer resist system. Ti/Au $(3 / 30 \mathrm{~nm})$ contacts were then evaporated followed by a lift-off. A consequent EBL and DC magnetron sputtering steps were used to pattern the $\mathrm{Nb} / \mathrm{Pd}$ lines together with the DC contact pads. The $\mathrm{NbN}$ bridge width $(800 \mathrm{~nm})$ between the contact pads was defined by a negative e-beam resist etch mask and further reactive etching in $\mathrm{CF}_{4} / \mathrm{O}_{2}$ gas mixture. The negative resists mask was left on top of the HEB bridge as a protection against degradation factors.

\subsection{Characterization}

In order to determine the microstructure, the crystallographic orientation and the composition of the layer system NbN/3C-SiC, including the interface region, an aberration corrected (Cs) Titan 80-300 High Resolution Transmission Electron Microscopy (HRTEM), equipped with a scanning module a High Angle Annular Dark Field detector (HAADF) and an Energy Dispersive X-Ray detector (EDX) was used.

$\mathrm{X}$-ray diffraction (XRD) measurements were utilized for verification of the epitaxial relation between the lattice parameters of the $\mathrm{NbN}$ film and the $3 \mathrm{C}-\mathrm{SiC}$ substrate. For these purposes, a Phillips X'Pert Diffractometer with $\mathrm{Cu} \mathrm{K} \alpha$ source $\left(\lambda_{\mathrm{Cu}}{ }^{\mathrm{K} \alpha}=1.540598 \AA\right)$ operated at $40 \mathrm{~mA}$ and $40 \mathrm{kV}$ was employed. For two-dimensional mapping, we have used a Ge(220) 4-crystal monochromator with crossed slits as primary optics, while for secondary optics, a triple axis module was applied. For x-ray reflectometry measurements of the film thickness, we used line focus and thin-film collimator module with a $1 / 16^{\circ}$ fixed slit as secondary optics.

Measurements of the temperature dependence of the deposited $\mathrm{NbN}$ films' resistivity, as well as current-voltage characteristics of the fabricated HEB devices were done through a standard four-probe technique in a LHe dewar. The samples were glued on a fiberglass fixture and the individual HEB devices were connected through wire bonding. The temperature during the DC measurements was read from calibrated Si-diode temperature sensor.

\section{Results and discussion}

\subsection{Structure of the NbN/3C-SiC interface}

High Resolution Transmission Electron Microscopy (HRTEM) cross-section images of an NbN sample grown on 3C-SiC substrate confirmed the complete epitaxial nature of the deposited films. The HRTEM presented in figure 1 evidences the crystalline quality of the $5 \mathrm{~nm}$ thick $\mathrm{NbN}$ film (cf. the included diffraction pattern, figure 1). Along the NbN/3C-SiC interface, one could though notice a partially amorphous interlayer, with a thickness of about three atomic distances. We suggest that this is due to applied RF sputter-cleaning with argon ions prior to deposition, which might have caused a radiation damage to the $3 \mathrm{C}-\mathrm{SiC}$ substrate. However, optimization of the plasma cleaning conditions may eliminate this problem. It is worth mentioning that although causing some stacking faults in the $\mathrm{NbN}$ layer, the amorphous interlayer did not preclude the epitaxial growth of $\mathrm{NbN}$. The reason for this behaviour is the fact that not the complete interface in question is amorphous, but in certain parts a direct contact between crystalline $\mathrm{NbN}$ and $3 \mathrm{C}-\mathrm{SiC}$ is given, enabling the observed epitaxial growth. The thickness of the film was also been confirmed to be $5 \mathrm{~nm}$, which was expected from our deposition rate calibration.

The $\mathrm{NbN}$ films has been also examined by X-ray diffraction (figure 2). In comparison with the XRD results presented in $[14,17]$, where relatively thick films were studied, we present the XRD data obtained on the same $5 \mathrm{~nm}$ thick NbN studied by HRTEM and with $T_{\mathrm{c}}$ as further shown in figure 3 . Figure 2(a) shows the XRD pattern of a 3C-SiC film deposited on a Si substrate with (100) orientation. The broad $3 \mathrm{C}-\mathrm{SiC}$ substrate peak indicates that this layer has a wide range of lattice parameters. XRD area scan of the $\mathrm{NbN}$ and the underlying $3 \mathrm{C}-\mathrm{SiC}$ layer is shown in figure 2(b). The broadening of the contours in $2 \theta$, just as in the single scan of figure 2(a), points towards the large variation of the lattice parameter of the substrate. Note that both substrate and the NbN layer diffraction peaks of the (200) reflection have not been resolved as they virtually occupy the same location at about $41.4^{\circ}$, 
corresponding to a lattice parameter $a=4.3584 \AA$, indicating that on average this film is strained to the $3 \mathrm{C}$-SiC. Moreover, the overlapping of the peaks agrees with the diffraction patterns presented in figure 1 . This data largely coincide with the results presented in [17].

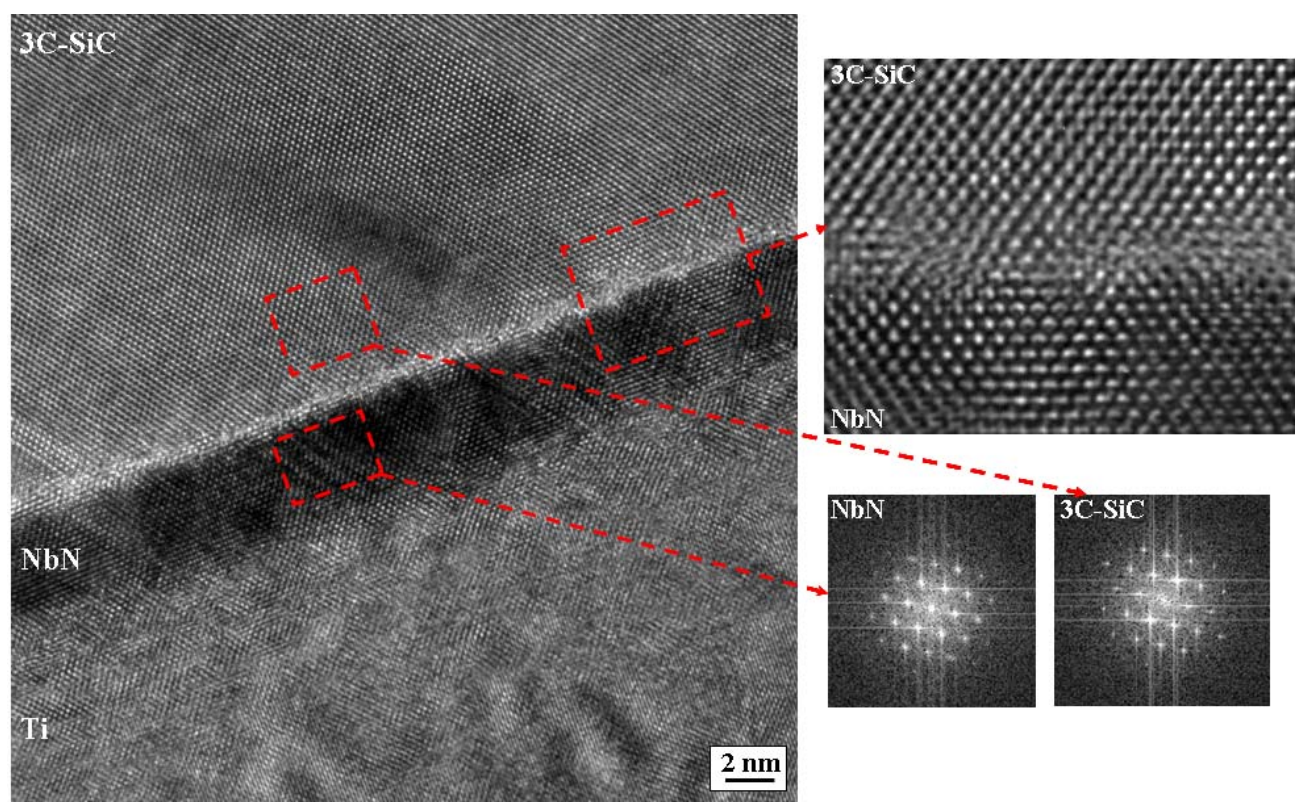

Figure 1. Cross-sectional HRTEM images of epitaxial $\mathrm{NbN}$ film grown on 3C-SiC/Si substrate. To the right are enlargements of the indicated areas, presenting the $\mathrm{NbN} / 3 \mathrm{C}-\mathrm{SiC}$ interface and corresponding diffraction pattern calculated by Fourier transformation of the related image areas.

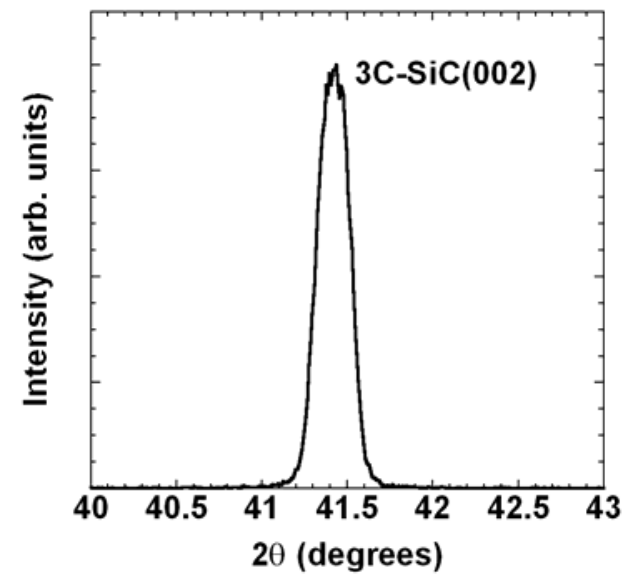

(a)

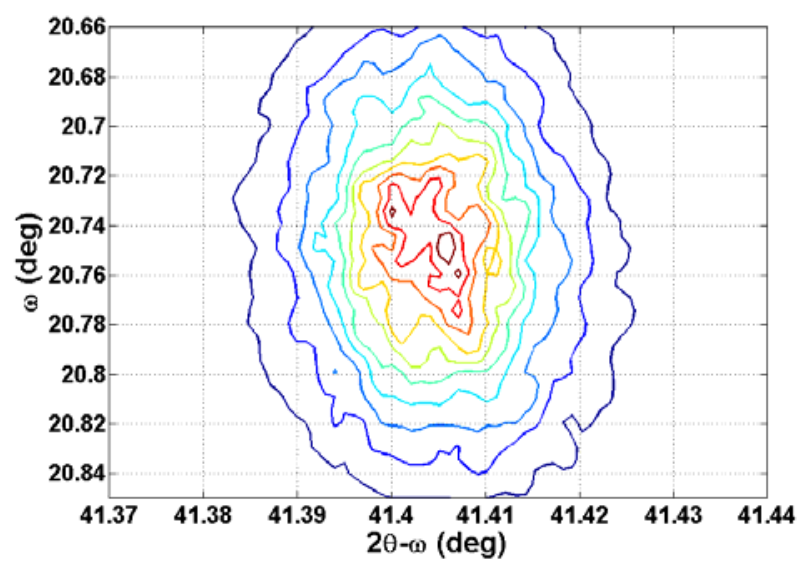

(b)

Figure 2. (a) XRD pattern of a 3C-SiC layer on a Si substrate with (001) orientation. (b) XRD area scan of the NbN/3C-SiC layer system. The contours indicate the diffracted intensity on a logarithmic scale. In the plot, the substrate (3C-SiC) peak dominates the spectrum.

\subsection{Electrical and superconducting properties of $\mathrm{NbN} / 3 \mathrm{C}$-SiC HEBs}

The measured temperature dependence of the resistivity of the un-patterned ultra-thin $\mathrm{NbN}$ film with the structural properties described above is shown in figure 3. The critical temperature for the presented unpatterned ultra-thin $\mathrm{NbN}$ film on $3 \mathrm{C}-\mathrm{SiC} / \mathrm{Si}$ substrate, estimated from the middle of the 
transition (10\%-90\%), corresponds to $11.8 \mathrm{~K}$, which is similar to the $T_{\mathrm{c}}$ of the $\mathrm{NbN}$ film presented in [14]. We observed a transition width $\left(\Delta T_{\mathrm{c}}\right)$ of $0.8 \mathrm{~K}$ for our $\mathrm{NbN}$ film, which is about $0.3 \mathrm{~K}$ narrower than that estimated from the figure 3 from [17]. We attribute the sharper transition to the enhanced structural properties of the $\mathrm{NbN}$ film which could be a consequence of the different 3C-SiC growth method, produced by the hot-wall CVD technique. The narrower superconducting transition width directly improves the conversion efficiency and noise performance of the HEB mixer [20].

In order to assess the properties of the epitaxially grown ultra-thin $\mathrm{NbN}$ films on $3 \mathrm{C}-\mathrm{SiC}$ for further possible use for HEB devices, a number of HEB structures with various bridge lengths have been fabricated.

Further, we discuss the DC properties that can be used as performance indicators to verify the quality and uniformity of the film. We have found that the fabricated devices provide consistently similar DC characteristics, which proves that our analysis is representative. Figure 4 shows the average resistance at $20 \mathrm{~K}$ of 24 measured devices in this batch as for each bridge length up to 7 devices were measured. The measured normal state resistance takes into account not only the resistance of the $\mathrm{NbN}$ film between the contact pads but also includes the contribution of the resistance at the $\mathrm{NbN}$ and $\mathrm{Ti} / \mathrm{Au}$ interface. Commonly, the Ti/Au contact pads are formed $e x$-situ and without additional cleaning of the $\mathrm{NbN}$ film prior to evaporation. This largely defines the contact resistance between the $\mathrm{NbN}$ film and the Ti/Au contact pads [21-23]. Additionally, due to a noticeable conductivity of the $3 \mathrm{C}-\mathrm{SiC} / \mathrm{Si}$ substrate, the film resistivity at room temperature is difficult to estimate. Therefore, the measurements were performed at $20 \mathrm{~K}$ where the conductivity of the substrate is considered negligible due to carrier freeze-out. The measured bridge resistance $(R)$ at $20 \mathrm{~K}$ scales linearly with the device length $(l)$, Fig. 4 . The total bridge resistance according to the transmission line model (TLM) [24] is $R=2 R_{\mathrm{C}}+R_{\square} l / w$, where $w$ is the bridge width, $R_{\square}=500 \pm 50 \Omega /$ square is the film sheet resistance and $R_{C}=50 \pm 5 \Omega$ is the contact resistance. We assume the $R_{C}$ remains the same for all bridge lengths by keeping the same device geometry and applying the same processing technique.

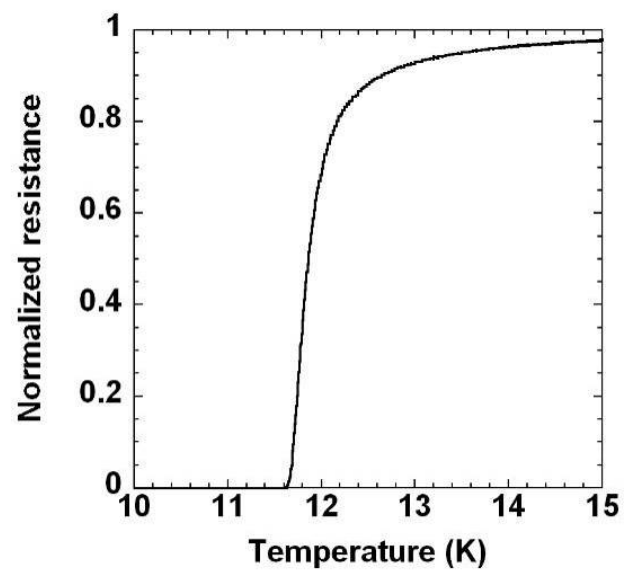

Figure 3. Critical temperature for an ultra-thin $\mathrm{NbN}$ film grown on a $3 \mathrm{C}-\mathrm{SiC} / \mathrm{Si}$ substrate.

Figure 5 displays the measured critical current and critical temperature data. We observed that independently on the bridge length, the critical current values were in the range from $100 \mu \mathrm{A}$ to $120 \mu \mathrm{A}$. Similarly, the critical temperature values for the processed bridges were about $11.3 \mathrm{~K}$ and independent on their length. This confirms the uniformity of the produced ultra-thin $\mathrm{NbN}$ film. The measured values of the critical temperature for the patterned HEB structures are close to the value of the unprocessed film suggesting that there is nearly no processing related damage to the $\mathrm{NbN}$ film. 


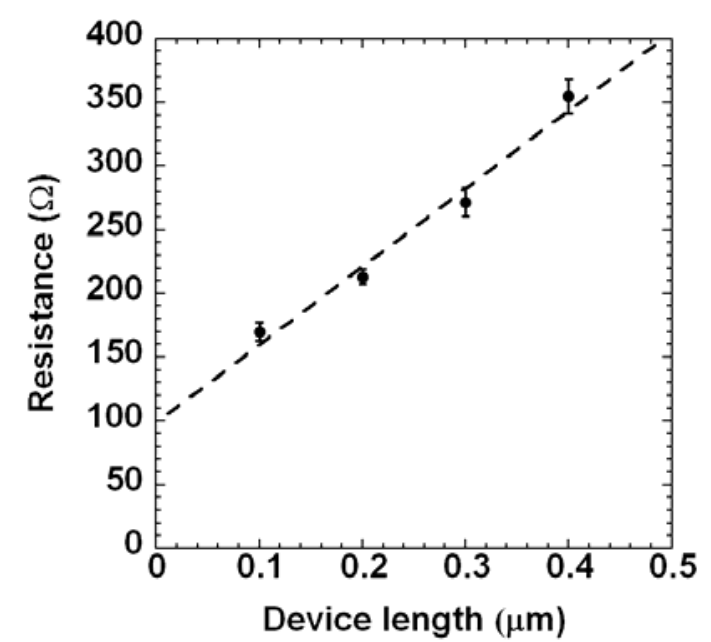

Figure 4. Measurements of the normal-state resistances at $20 \mathrm{~K}$ as a function of the bridge length. The dashed line represents the best linear

fit to the measured values. The error bars represent the standard error of the measured data.

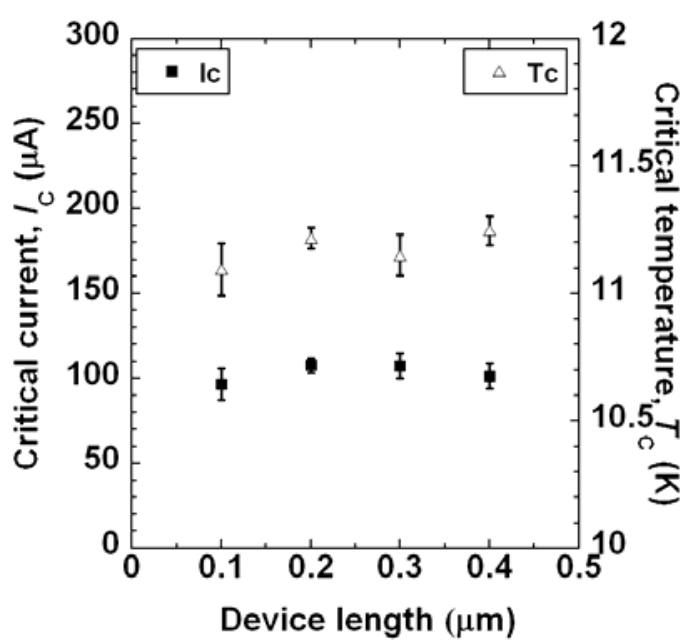

Figure 5. Dependence of the critical temperature and critical current on the bridge length. The error bars represent the standard error of the measured data.

We have studied the temperature dependence of the critical current density in the $\mathrm{NbN}$ bridges on 3C$\mathrm{SiC}$ by measuring the current-voltage $(I-V)$ characteristics in the temperature interval from $4.2 \mathrm{~K}$ to the critical temperature. Additionally, we have fabricated a batch of similar bridges (28 measured devices) made of thin $\mathrm{NbN}$ film (see table 1), grown on a crystal quartz substrate [25]. The quartz substrate was used because it has an advantage of having low dielectric constant and low RF losses, a combination very suitable for $\mathrm{THz}$ waveguide applications [5]. We assume that both samples have the same contact resistance because of the identical fabricating process parameters. The value of the sheet resistance of the $\mathrm{NbN}$ on quartz is lower than our deposited $\mathrm{NbN}$ film, which implies that the reference $\mathrm{NbN}$ film is likely thicker. Table 1 summarizes the data of the measured bridges.

Table 1. Normal-state and superconducting properties of the samples.

\begin{tabular}{lcccccc}
\hline Substrate & $R_{20 \mathrm{~K}}(\Omega)$ & $\begin{array}{c}l \\
(\mathrm{~nm})\end{array}$ & $\begin{array}{c}w \\
(\mathrm{~nm})\end{array}$ & $\begin{array}{c}d \\
(\mathrm{~nm})\end{array}$ & $\begin{array}{c}T_{\mathrm{C}} \\
(\mathrm{K})\end{array}$ & $\begin{array}{c}j_{\mathrm{C}}(0) \\
\left(\mathrm{MA} / \mathrm{cm}^{2}\right)\end{array}$ \\
\hline 3C-SiC/Si & $213 \pm 12^{\mathrm{a}}$ & 200 & 800 & $5^{\mathrm{b}}$ & 11.3 & 3.05 \\
Quartz & $135 \pm 15^{\mathrm{c}}$ & 100 & 800 & $8.6 \pm 1.7^{\mathrm{d}}$ & 9.3 & 1.14 \\
\hline
\end{tabular}

a The average bridge resistance $\left(\mathrm{R}_{20 \mathrm{~K}}\right)$ on the $3 \mathrm{C}-\mathrm{SiC} / \mathrm{Si}$ substrate is taken over 7 samples.

${ }^{\mathrm{b}}$ Obtained from HRTEM image, Fig. 1.

${ }^{c}$ The average bridge resistance $\left(\mathrm{R}_{20 \mathrm{~K}}\right)$ on the quartz substrate is taken over all 28 samples.

${ }^{\mathrm{d}}$ The film thickness is estimated based on scaling of the bridge resistance with the film thickness, assuming the samples on both substrates have the same contact resistance and both $\mathrm{NbN}$ films have the equal specific resistance.

The temperature dependence of the measured critical current density $\left(j_{\mathrm{C}}\right)$ in the $\mathrm{NbN}$ bridges on $3 \mathrm{C}$ $\mathrm{SiC}$ is presented in figure 6 . The dashed line represents the temperature dependence of the de-pairing critical current [26], followed from the Ginzburg-Landau theory:

$$
j_{C}(t)=j_{C}(0)\left(1-t^{2}\right)^{3 / 2}\left(1+t^{2}\right)^{1 / 2}
$$

where $t=T / T_{\mathrm{C}}$ and $j_{\mathrm{C}}(0)$ is the density of the de-pairing critical current at $0 \mathrm{~K}$. Measured $j_{\mathrm{C}}(T)$ data for the bridges made of $\mathrm{NbN}$ ultra-thin film grown on both type of substrates follow the theoretical relation (1) over the complete measured temperature range. Fitting of experimental data for $j_{\mathrm{C}}(\mathrm{T})$ with 
the relation (1) allows to extract $j_{\mathrm{C}}(0)$ value for the films, grown on both types of substrates as shown in table 1 . The difference (more than 2 times) between the values for the critical current density could be explained by the different values of the critical temperature of $\mathrm{NbN}$ film, grown on $3 \mathrm{C}-\mathrm{SiC} / \mathrm{Si}$ and crystal quartz substrates.

To our knowledge, the work presented here is the first to report on extensive DC characterization of fabricated HEB devices on epitaxial ultra-thin $\mathrm{NbN}$ films grown on single-crystal 3C-SiC layer. Therefore, we consider the data from the DC characterization as a useful complement to the work presented in [14] and [17], where only a temperature-resistance curves of a plain $\mathrm{NbN}$ films have been shown.

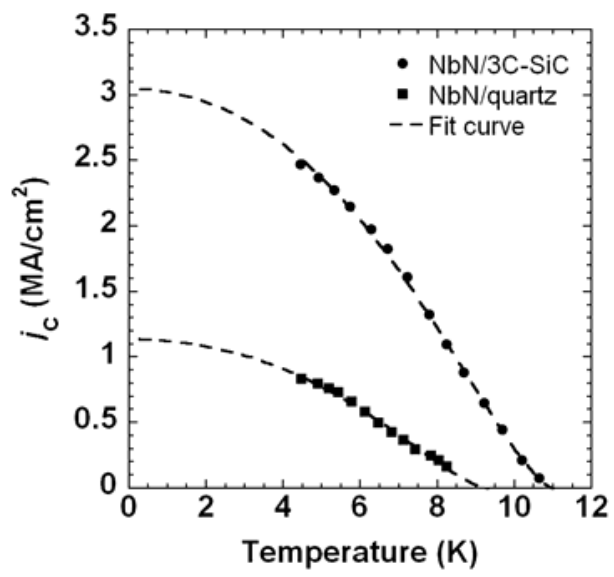

Figure 6. Critical current density as a function of temperature for $\mathrm{NbN}$ grown on $3 \mathrm{C}-\mathrm{SiC}$ and single crystal quartz substrates. The dashed lines represent the temperature dependence of the de-pairing critical current density according to (1).

\section{Conclusions}

The presented experimental work on deposition and characterization of ultra-thin $\mathrm{NbN}$ films on $3 \mathrm{C}$ $\mathrm{SiC} / \mathrm{Si}$ substrate demonstrated that the use of monocrystalline 3C-SiC/Si substrates provides good lattice matching with $\mathrm{NbN}$, resulting in epitaxial growth of ultra-thin $\mathrm{NbN}$ films. The complete epitaxial growth of $\mathrm{NbN}$ outcomes in an improvement of the superconducting film properties. The highest $T_{\mathrm{C}}$ value obtained for the $5 \mathrm{~nm}$ thick epitaxial films was $11.8 \mathrm{~K}$. The processed NbN HEBs had a similar critical current density of $\sim 2.5 \mathrm{MA} / \mathrm{cm}^{2}$ at $4.2 \mathrm{~K}$ across the wafer. We conclude that the epitaxial $\mathrm{NbN}$ films grown on $3 \mathrm{C}-\mathrm{SiC} / \mathrm{Si}$ substrate have a good potential to be used in $\mathrm{THz} \mathrm{HEB}$ mixers with the purpose for further IF bandwidth improvement.

\section{Acknowledgements}

Erik Sundin and Hawal Rashid are acknowledged for their assistance during the DC characterization. This work was supported by the European Commission Framework Programme 7, Advanced Radio Astronomy in Europe, AMSTAR+, grant no. 227290.

\section{References}

[1] Cherednichenko S, Drakinskiy V, Berg T, Khosropanah P and Kollberg E. 2008 Rev. Sci. Instrum. 79034501

[2] Marrone D P, Blundell R, Tong E, Paine S N, Loudkov D, Kawamura J H, Luhr D and Barrientos C 2004 Proc. $15^{\text {th }}$ Int. Space Terahertz Technol. Symp. (Northampton, MA, USA 27-29 April 2004) p 64

[3] Meledin D et al. 2004 IEEE Trans. Microwave Theory Tech. 522338

[4] Belitsky V et al. 2007 Proc. Joint $32^{\text {nd }}$ Int. Conf. Infrared Millimeter Waves and $15^{\text {th }}$ Int. Conf. Terahertz Electron. (Cardiff, England 3-9 Sept. 2007) p 320 
[5] Meledin D et al. 2009 IEEE Trans. Microwave Theory Tech. 5789

[6] Khosropanah P, Gao J R, Laauwen W M, Hajenius M and Klapwijk T M 2007 Appl. Phys. Lett. 91221111

[7] Ryabchun S A, Tretyakov I V, Finkel M I, Maslennikov S N, Kaurova N S, Seleznev V A, Voronov B M and Gol'tsman 2009 Proc. 20th Int.Symp. Space THz Technology (Charlottesville, USA 20-22 April 2009) p 151

[8] Kaplan S B 1979 J. Low Temp. Phys. 37 343-365

[9] Meledin D, Tong C Y E, Blundell R, Kaurova N, Smirnov K, Voronov B and Gol'tsman 2002 Proc. 13th Int.Symp. Space THz Technology (Cambridge, MA, USA 26-28 March 2002) p 65

[10] Ekström H, Kollberg E, Yagoubov P, Gol'tsman G, Gershenzon E and Yngvesson S 1997 Appl. Phys. Lett. 703296

[11] Gol'tsman G N et al. 2005 Proc. SPIE 5727 95-106

[12] Meledin D, Tong C Y E, Blundell R, Kaurova N, Smirnov K, Voronov B and Gol'tsman G 2003 IEEE Trans. Appl. Supercond. 13 164-167

[13] Faley M I, Mi S B, Petraru A, Jia C L, Poppe U and Urban K 2006 Appl. Phys. Lett. 89082507

[14] Shoji A, Kiryu S and Kohjiro S 1995 IEEE Trans. Appl. Supercond. 52396

[15] Villegier J C et al. 2009 IEEE Trans. Appl. Supercond. 193375

[16] Gao J R, Hajenius M, Tichelaar F D, Voronov B, Grishina E, Klapwijk T M, Gol'tsman G and Zorman C A 2006 Proc. 17th Int. Symp. Space and THz Technol. (Paris, France 10-12 May 2006) pp 187-189

[17] Gao J R, Hajenius M, Tichelaar F D, Klapwijk T M, Voronov B, Grishina E, Gol'tsman G, Zorman C A and Mehregany M 2007 Appl. Phys. Lett. 91062504

[18] Henry A, Hassan J, Bergman J P, Hallin C and Janzén E 2006 Chem. Vap. Deposition 12475

[19] Kordina O, Hallin C, Henry A, Bergman J P, Ivanov I, Ellison A, Son N T and Janzén E 1997 Phys. Status Solidi B 202321

[20] Gershenzon E M, Gol'tsman G N, Gogidze I G, Gusev Y P, Elantiev A I, Karasik B S and Semenov A D 1990 Superond. 31582

[21] Semenov A D, Hübers H -W, Schubert J, Gol'tsman G N, Elantiev A I, Voronov B M, and Gershenzon E M 2000 J. Appl. Phys. 886758

[22] Baselmans J J A, Hajenius M, Gao J R, de Korte P A J, Voronov B and Gol'tsman G 2004 Appl. Phys. Lett. 841958

[23] Il'in K S, Stockhausen A, Scheuring A, Siegel M, Semenov A D, Richter H and Huebers H -W 2009 IEEE Trans. Appl. Supercond. 19269

[24] Berger H. H. 1972 Solid-State Electron. 15145

[25] NbN film is fabricated by Moscow State Pedagogical University, Moscow, Russia

[26] Skocpol W J, Beasley M R and Tinkham M 1974 J. Appl. Phys. 454054 